\title{
Cloud Computing in Education in Developing Countries
}

\author{
Faten Karim $^{1,2}$ \& Giselle Rampersad ${ }^{1}$ \\ ${ }^{1}$ School of Computer Science Engineering and Mathematics, Flinders University, South Australia, Australia \\ ${ }^{2}$ College of Computer Science, Princess Nourah bint Abdulrahman University, Riyadh, Saudi Arabia \\ Correspondence: Faten Karim, School of Computer Science Engineering and Mathematics, Flinders University, \\ South Australia, Australia. E-mail: faten_karime@yahoo.com
}

Received: March 23, 2017

Accepted: April 11, 2017

Online Published: April 30, 2017

doi:10.5539/cis.v10n2p87

URL: https://doi.org/10.5539/cis.v10n2p87

\begin{abstract}
The main advantage of cloud computing is to reduce the IT cost. By using cloud computing, organisations do not have to set up an IT infrastructure, and instead are able to rent resources and give payment only for the using services. Even with the appealing of cloud computing benefits, it is still in infancy in developing countries due to many reasons. Technology adoption has been explored to a limited degree in developing countries, particularly in relation to cloud computing in the tertiary education sector. Existing studies have examined technology adoption in developed countries and to a lesser extent in developing countries in non-education contexts such as e-government. This paper contributes to the cloud computing adoption literature in developing countries, and specifically in Saudi Arabian universities.
\end{abstract}

Keywords: cloud computing, developing countries, education

\section{Introduction}

Cloud computing has a wide range of characteristics that enables it to be at the forefront of computing technology such as flexibility according to the scale and levels of demand. Distinctive virtual and physical resources are allocated and reallocated to enhance services according to consumer demand. In addition, computing facilities are accessible through any device that is available, such as smartphones, tablets, laptops, and desktop computers (Mell \& Grance, 2011; Zhang, Cheng, \& Boutaba, 2010). Moreover, one of the most significant characteristics of cloud computing is reduced costs. The flexibility and scalability of cloud computing allows cloud clients to avoid the expenditure of installing and maintaining many computing facilities (Linthicum, 2009). Furthermore, one of the main goals of adopting cloud computing is to cut down the infrastructure expenditure, either information technology (IT) equipment or staff. Cloud computing is an affordable, flexible, reliable and highly efficient technology.

Based on the above characteristics of cloud computing, it is clear that higher education systems can benefit from cloud capabilities, increasing internal efficiency and educational capabilities. The following sections cast light on the benefits of cloud based education and covers the particular relevance of cloud computing for education in Saudi Arabia as a developing country, including the unique characteristics of academic institutions, potential benefits, and the barriers to adopting cloud computing.

\section{Benefitting from the Cloud in the Educational Sector}

Several factors have a positive effect on the adoption of cloud computing in educational organisations. As cloud computing can provide infrastructure as a service, it provides a variety of advantages over traditional systems. From the outset, the centralised infrastructure of a cloud system reduces the need for task repetition on the local level at which the system is deployed, and thus decreases the resources, cost and time, needed to structure the infrastructure (Aljenaa et al., 2011). Another aspect is the agile nature of deployment. Once a cloud is running, the deployment process is swift across the organisation because of the reduced need for technical work to implement the services in individual schools or departments. Computers with minimal specifications, capable of launching a web browser, can be utilised as a web based platform for interactive learning (Aljenaa, Al-Anzi, \& Alshayeji, 2011). Furthermore, educational institutions can benefit from the off-the-shelf SaaS, PaaS and IaaS without the burden of infrastructure set-up or maintenance (Kaur, 2015).

Another benefit of using cloud computing is that courses dispensed via cloud computing through a central location will result in standardised content delivery to numerous simulated classrooms. This can impart synchronicity and 
consistency in learning and training at multiple locations, while ensuring students receive identical study material. Kaur (2015) points out that with cloud technology in place, distance learning classrooms can be maintained by a small group which is useful in cases of shortages of qualified staff.

Also, Kaur (2015) states that cloud computing provides course content backup which eliminates the risk of losing data in instances of system crashes. Various content types can be stored in the cloud, such as audio/video, documents, and applications. Pardeshi (2014) and Weaver (2013) mentioned that by using cloud computing, multiple students can work together on the same document simultaneously.

In the sphere of cloud computing, Kaur (2015) notes that software is updated automatically, providing the latest version of software. Administrative staff and educators can focus more on their institutional needs, rather than losing time on IT infrastructure and applications set-up. Thus, all the administrative activities will be performed in a speedier and more effective manner. Lakshminarayanan, Kumar, and Raju (2013) argue that using cloud computing will free IT staff from maintenance and update support.

On the basis of the above, it can be concluded that cloud computing provides solutions and improvements to higher education institutions. The use of the cloud helps to standardise and update educational contents, facilitates the collaboration between students and between the students and the teacher. Educational institutions benefit by overcoming the lack of IT staff and at the same time are freed from the burden of updating and maintaining the computer systems and applications. Moreover, by using cloud computing, system failure becomes less important because of the backup feature.

The majority of studies on cloud computing have occurred in the developed countries rather than developing countries. Troshani et al. (2011) have also explored organisational adoption of technology through TOE in a cloud computing context in the higher education sector (Troshani, Rampersad, \& Wickramasinghe, 2013; Troshani et al., 2011). However, this study was based in Australia, a developed country, rather than a developing country.

IT adoption has been explored to a limited degree in developing countries, particularly in relation to cloud computing in the tertiary education sector. Existing studies have examined IT adoption in developing countries in non-education contexts such as e-government. For instance, Susanto and Goodwin (2010) examined the context of e-government adoption in Indonesia, and other authors have examined technology e-services adoption in Saudi Arabia (Aldraehim, 2013; Aldraehim et al. 2013; 2012a; 2012b; Aldraehim, Edwards \& Watson, 2012). In addition, other authors examined IT adoption within the e-government context in Saudi Arabia (Alghamdi et al., 2011a; 2011b; 2013; 2014; Alzahrani \& Goodwin, 2012; Alzharani, 2015). In addition, Rosli et al. (2012) investigated IT adoption of audit technology among Malaysian audit firms. While these studies have been useful in shedding light on pertinent factors influencing IT adoption in developing countries, more research is needed in the context of higher educational institutions in such countries.

\section{Cloud Computing in Developing Countries}

Cloud computing is still in an early phase in developing countries due to a lack of awareness of the possibilities of ICTs (Kshetri, 2010). The international IT market, with help of developing countries' governments, has therefore paid much attention to introducing and encouraging the use of cloud computing. For example, IBM (the largest computer company in the worldwide) instituted cloud computing centres in China, India, Vietnam, Brazil, and South Korea. Other big companies like DELL and Microsoft are actively trying to find and make use of opportunities in developing countries (Kshetri, 2010).

As noted in 2016 by the International Trade Administration (ITA) in the United States, a list of top 20 cloud computing export markets for the US IT industry (Table 1) include developing countries which have made significant developments in their ICT sectors (ITA, 2016).

Table 1. Top cloud computing export markets (through 2016) (ITA, 2016)

\begin{tabular}{|l|l|}
\hline 1 Canada & 11 China \\
\hline 2 Japan & 12 France \\
\hline 3 United Kingdom & 13 Netherlands \\
\hline 4 Brazil & 14 Italy \\
\hline 5 South Korea & 15 Sweden \\
\hline 6 Germany & 16 Singapore \\
\hline 7 Switzerland & 17 Spain \\
\hline 8 India & 18 South Africa \\
\hline
\end{tabular}




\begin{tabular}{|l|l|}
9 Mexico & 19 Chile \\
\hline 10 Australia & 20 Malaysia \\
\hline
\end{tabular}

In developing countries, cloud activities are centred on the larger economies, as China, India, South Africa and Vietnam (Kshetri, 2010). The biggest computing services market in Latin America is in Brazil, followed by Mexico and Chile. South Korea has a ready infrastructure and government financing, which enable the county to own one of the most stable cloud computing markets. Also in India, the government pays great attention to improvements in infrastructure and Internet access (Kshetri, 2010). China is adopting technology quickly in a rapidly expanding market. China's market features expertise, resources and commitment, which makes it appealing to the global cloud computing market (ITA, 2016).

In addition, the Gulf Arab countries are moving speedily towards cloud computing (Zeineldin, 2014). The DELL company reported that it will provide cloud service capabilities to companies in Saudi Arabia and the Middle East (Dickinson, 2015).

Table 2. Cloud application sectors that are being explored in developing countries (Kshetri, 2010)

\begin{tabular}{lllllll}
\hline Country & E-education & E-health & E-commerce & E-governance & E-environment & Tele commuting \\
\hline China & $\mathrm{X}$ & $\mathrm{X}$ & $\mathrm{X}$ & & $\mathrm{X}$ & \\
East Africa & $\mathrm{X}$ & & & & \\
India & $\mathrm{X}$ & $\mathrm{X}$ & & & \\
Korea & & & $\mathrm{X}$ & & $\mathrm{X}$ \\
Qatar & $\mathrm{X}$ & & & & \\
South Africa & & $\mathrm{X}$ & & \\
Turkey & $\mathrm{X}$ & & & $\mathrm{X}$ & \\
Vietnam & $\mathrm{X}$ & & & & & \\
West Africa & & & & & & \\
\hline
\end{tabular}

As illustrated in Table 2, e-education is the most popular area to employ cloud computing in developing countries. South African universities benefit from cloud computing in medical research, while in East Africa, a group of seven universities is working on virtual computing labs that enable students to work from a distance (Kshetri, 2010).

Universities in China, Turkey, and Qatar are participating in the IBM Cloud Academy. In addition, Chinese universities analyse disease spread patterns and climate change data by using supercomputers. Indian universities make use of the big storage in cloud computing to develop innovative research, and Vietnamese government organisations and universities utilize the cloud in developing educational applications (Kshetri, 2010).

\subsection{The Existing State of Cloud Computing in Saudi Arabia}

Cloud computing is being applied in the Saudi Arabian context without adapting approaches to suit local needs. Consequently, attention is critically needed in this area. According to BMI (2014) (Business Monitor International, a Fitch Group Company), the adoption of cloud computing services in Saudi Arabia will soon produce rapid growth in that technological area. The government is investing widely in e-government applications to improve facilities provided by the public sector, and making use of cloud computing services. The e-government program (YESSER) mentions in its website (Yesser, 2016) that

The government cloud computing initiative provides government agencies with ready services of high efficiency, reliability and security with respect to infrastructure, platform, and software all as a service.

Government secure network, government service bus and e-correspondence are examples of available cloud based services. ICT industry experts expect that cloud computing and mobility will be the foundation of the strongest ICT investments in Saudi, mainly on the private cloud model (CITC, 2015). The International Data Corporation (IDC) predicts a sharp increase in cloud services in Saudi equivalent to compound annual growth rate of 57.7\% over the period extending through 2017 (IDC, 2014). The IDC (2014) have pointed out that data security concerns are the drivers behind national enterprises preferring the adoption of the private cloud over the public in order to keep the data under their control and management. Buller (2016) notes that Saudi Arabia would like to have a public cloud locally and under their control, but due to the deficiency of infrastructure and skills, this is currently difficult. Currently two telecommunication companies have taken the chance to provide 
cloud services in Saudi Arabia (Alsanea, 2015), but despite this evolution, many challenges still exist, such as resolving data ownership, shortage of cloud regulations and national cloud strategies (Buller, 2016). As a response to the lack of cloud regulations, the Communication and Information Technology Commission in Saudi Arabia (CITC) has proposed new regulations to support cloud computing developments in Saudi Arabia (CITC, 2016).

\subsection{Cloud Computing Literature in Education in Saudi Arabia}

Literature relating to cloud computing in the education sector in Saudi Arabia is scarce. Most of the cloud computing Saudi studies are about users' acceptance, attitudes, and adoption of cloud computing in areas other than education; they are mostly in e-government and e-commerce (Table 3).

Al-Somali and Baghabra (2016) targeted IT professionals from private and government organisations in Saudi Arabia to examine a model of cloud-based applications adoption. They found that technology accessibility, perceived vulnerabilities, individual characteristics and social image are all significant factors in cloud computing applications usage.

Mezghani and Ayadi (2016) studied factors that cause a negative attitude toward cloud computing adoption in Saudi firms. The findings showed that a focus on risk factors promoted negativity, whereas the positive perceptions of the cloud, like perceived benefits, perceived ease of use and perceived usefulness, resulted in a positive approach to cloud computing.

Yamin and Al Makrami (2015) investigated the extent of using cloud computing in SMEs in Saudi Arabia. Alhammadi, Stanier, and Eardley (2015) discuss a model to support decision makers to migrate to cloud computing. Yamin and AlMakrami (2015) compared the results of their research with the results of other research in developed countries in technological context.

Table 3. Cloud computing studies in Saudi Arabia

\begin{tabular}{|c|c|c|}
\hline Source & Subject studied & Field \\
\hline Al-Somali \& Baghabra, 2016 & Intention to use Cloud-based Application & Saudi organisations \\
\hline Mezghani \& Ayadi, 2016 & Managers attitudes & Saudi firms \\
\hline Yamin \& Al Makrami, 2015 & Cloud computing applications & $\begin{array}{l}\text { Saudi SMEs (Small \& } \\
\text { Medium sized Enterprises) }\end{array}$ \\
\hline Tashkandi and Al-Jabri ,2015 & Cloud computing adoption & $\begin{array}{l}\text { Saudi higher education } \\
\text { institutions }\end{array}$ \\
\hline $\begin{array}{l}\text { Alhammadi, } \quad \text { Stanier, } \quad \& \\
\text { Eardley, } 2015\end{array}$ & $\begin{array}{l}\text { strategic decision making for cloud } \\
\text { computing migration }\end{array}$ & \\
\hline Alsanea, 2015 & Cloud computing adoption & Saudi government sector \\
\hline $\begin{array}{l}\text { B. H. Alamri and Qureshi, } \\
2015\end{array}$ & Usability of cloud computing & $\begin{array}{l}\text { Saudi higher education } \\
\text { institutions }\end{array}$ \\
\hline Alkhater et al., 2014 & Cloud computing adoption & Saudi enterprises \\
\hline Alotaibi, 2014 & $\begin{array}{l}\text { Cloud computing users' attitudes and } \\
\text { intentions }\end{array}$ & \\
\hline Alharbi, 2012; & Users' acceptance of cloud computing & \\
\hline $\begin{array}{l}\text { El-Sofany, } \quad \text { Al-Otaibi, \& } \\
\text { Alsanea, } 2012\end{array}$ & Patient records exchange & Saudi hospitals \\
\hline Alshwaier , 2012 & $\begin{array}{l}\text { How cloud computing can benefit } \\
\text { e-learning education }\end{array}$ & E-learning in Saudi \\
\hline $\begin{array}{l}\text { Alshuwaier, Alshwaier, and } \\
\text { Areshey, } 2012\end{array}$ & Applications of cloud computing & Saudi education \\
\hline Chanchary \& Islam, 2011 & Users' acceptance & Saudi E-government \\
\hline
\end{tabular}


Alsanea (2015) and Chanchary and Islam (2011) conducted their studies in the Saudi government sector. Alsanea (2015) investigated the factors that affect cloud computing adoption in the Saudi government area and evolved a practical roadmap in order to lead government organisations to adopt cloud computing effectively. Chanchary and Islam (2011) discussed the current e-government system in Saudi Arabia and proposed a cloud based model with a rational inference agent that is anticipated to be more user-friendly. El-Sofany, Al-Otaibi, and Alsanea (2012) researched in Saudi hospitals and developed a conceptual framework for patient records exchanges between hospitals all over Saudi Arabia.

Tashkandi and Al-Jabri (2015) investigated the factors that affect cloud computing adoption in Saudi universities. The findings showed that relative advantage, data privacy and complexity are the most significant factors influencing the uptake and use of cloud computing.

Alamri and Qureshi (2015) attempted to understand the reasons and the needs behind adopting cloud computing in higher education in Saudi Arabia and discover the barriers to the learning process. The findings indicated that improvement in higher education is strongly related to exist of professionals working in industry and academia.

Alshwaier (2012) examined how e-learning education in Saudi Arabia gain benefits from cloud computing with regards to cost, efficiency, reliability, flexibility and security; while Alshuwaier, Alshwaier, and Areshey (2012) analysed cloud computing applications, clarified some educational and research production and assessed the successful application of cloud computing models at educational organization.

\section{How Cloud Computing Benefits Specific Situation in Developing Countries}

According to the previously discussed benefits of cloud computing in the education sector, it is obvious that cloud computing provides potential benefits for education in developing countries. The next sections will further explain how cloud computing has come to be considered the ideal solution in some situations in developing countries, highlight some characteristics of academic institutions, and finally clarify some of the obstacles to the adoption of cloud computing in developing countries.

The implementation of cloud computing promises to provide flexible, on demand computational resources and applications by providing consumers with timely access to resources and services, with reasonable expenditure, ensured SLA(Service Level Agreement) and abridged entry effort (Armbrust et al., 2010; Creeger, 2009; Ograph \& Morgens, 2008). With research and academic institutions in developing countries lacking cloud computing resources, services located in developed nations have proven to be financially attractive and developmentally advantageous. Cloud computing may be a viable resource and solution for particular educational institutions in various computing situations.

A large number of opportunities have emerged from the usage of cloud computing within developing countries looking for participated in global markets without the traditional infrastructure utilized to expedite trade (Laverty, 2011). The use of cloud facilities mitigates the cost concerns that particularly affect research and educational institutions in some developing countries, including larger institutions. Truong, Pham, Thoai, and Dustdar (2012) explained how cloud computing offerings could thus viably resolve issues for certain situations in educational institutions, especially:

- Research and educational institutions with unsatisfactory computing resources in some developing countries. It is worth mentioning that this is not the situation in all developing countries; countries like China have access to the TOP500 supercomputers (TOP500, 2016).

- High workload teaching academics, because teaching is often considered one of the most important obligations at the academic institutions in developing countries. Teaching loads are substantial, and accompanied by considerable workloads for production and dissemination of learning resources by the same key staff. Thus, it is readily evident that there is a strong need for on-demand resources to support teaching activities (Truong et al., 2012).

- Groups with a small number of members with very limited budgetary resourcing. Limitations to IT management sustainability are widely due to finance and resourcing issues (Truong et al., 2012).

- Women restricted by a culture which makes it difficult to access higher education or hampered by an early marriage or transportation difficulties benefit from the access to information and communication offered by the cloud (Al Alhareth et al. (2013).

\section{Characteristics of Academic Institutions in Some Developing Countries}

Distinguishing characteristics exist within research and teaching activities. For example, IT facilities like hardware and educational software in the universities of developing countries are used only during the teaching 
semester, and not on a 24/7 basis. This differs from 'regular' usage, for which the primary function is email and storage (Truong et al., 2012). All types of the afore-mentioned IT facilities can be obtained by different means through using the cloud computing. Furthermore, according to the literature, higher education institutions in developing countries are most often teaching-oriented rather than research-centred (Education, 2000; Rena, 2010; Truong et al., 2012).

In developing countries, highly trained and skilled workforces are produced at the university level. Generally, teaching is frequently assumed to be the key action in universities. Small numbers of research-oriented universities or specialised research institutions do exist, but their exist are rare when compared to teaching-oriented universities. With regard to teaching, computing facilities are needed for student laboratory and library systems (Truong et al., 2012). Resources of cloud computing for teaching are frequently controlled by financial limitations, and characterised by the next attributes (Truong et al., 2012) :

- There is a very high ratio of students to resources due to financial and expertise constraints, compared to the population; the number of universities is usually small. This can be seen in China and Vietnam. Resources shared by students, such as computer laboratories for practical courses, are often very limited.

- Commonly student laboratory hours' conflict with classes. Access to laboratory facilities is frequently quite limited.

- In developing countries, academic institutions require a great deal of resources in a specific, intensive period. The institutions, however, know in advance the extent of the required resourcing. Furthermore, due to high student numbers, these institutions would like to minimise reliance on computing laboratory services in order to decrease expenses, whilst increasing access to the services provided by the laboratories.

Cloud computing may hypothetically deliver a sturdy resolution for difficulties faced by educational and research institutions.

\section{Potential Benefits of Cloud Computing in Developing Countries}

Greengard (2010) has posited several benefits resulting from cloud computing in developing countries. These benefits include ease of access to affordable computing infrastructure, augmentation of collaborative efforts, and the ability to approach the up-to-date hardware and software. The following table summarises by what means cloud service models can be engaged in teaching.

Table 4. Engaging cloud service models in teaching, adapted from (Truong et al., 2012)

\section{Cloud service model Support for teaching activities}

Software as a Service

Student use of standardised applications for labs. For instance, Google Documents can aid students in practical activities or spreadsheet processes

Institutions could concurrently start educational software to decrease investment expenditure and to improve teamwork activities for the purpose of teaching.

Platform as a Service Mainly beneficial for students who could employ PaaS for learning programming (PaaS) tools. For instance, students could practice web programming by using Google App Engine.

Students in economic and computational field could utilise PaaS (such as MathLab and R platform) to customize their implementing and analysis tools.

Infrastructure as a Supply as requested machines for computer labs and personal use. Students can Service obtain customised virtual machines that might contain operating systems, laboratory exercises, and collaboration kits for their course work. From a university's perception, for processes that need heaps of machines within a limited time, such as parallel processing, IaaS could be utilized to reduce financial cost, and minimise logistical burdens.

Data-as-a-Service (DaaS) 


\section{Barriers to the Adoption of Cloud Computing in Developing Countries}

There are many logistical barriers to cloud computing adoption in developing countries that can be discussed together, namely: lack of connectivity, inadequate bandwidth, and unstable power supplies (Greengard, 2010). Jelonek and Wysłocka (2014) also added that the most critical barriers to the adoption of cloud computing in developing countries are: trust, security, portability, and the local language. Al Alhareth et al. (2013) tied the adoption of any new technology in Saudi with cultural beliefs since the society on the whole considers the adoption of any technology through the prism of beliefs and religious values, which it seeks to protect.

There exist several other adoption barriers for previously mentioned groups that are very specific to developing countries:

Cost. Cost-benefit analysis from existing clouds indicates high financial costs for research and educational categories in developing countries, relative to their income. These costs will need to be reduced in these contexts to enable access to cloud computing (Greengard, 2010).

Service and infrastructure readiness. Cloud computing infrastructure is not installed locally in developing countries. many impacts on technical issues such as performance can be enhanced, while data compliance concerns can be simplified (Greengard, 2010).

Cloud computing expertise. Research and educational categories in developing countries lack computational resources as well as cloud computing expertise. The usage of cloud computing is intended to reduce administrative load from non-IT staff, yet expertise in cloud computing is required. For example, there is a comprehensive deficiency of qualified IT experts, training programs and trained eLearning academics in the North African region (Greengard, 2010).

Information security concerns and compliance. In comparison to other consumers of cloud computing, research and educational professionals in developing countries share various security issues in case of implementing cloud computing. Instances of collective, generally articulated security trepidations are data protection, user lock-in, and deficiency in control. (Chow et al., 2009; Kaufman, 2009; Truong et al., 2012).

With regard to security apprehensions and compliances, in developed countries, these cloud technologies support law and regulations but they disregard legal restrictions and guidelines in developing countries. This is also a popular concern in any business in developing countries. Additionally, staff in public institutions must guarantee that the feature of paying according the usage follow government guidelines in relations to guarantee, liability, and insurance. These issues relate to cloud services as well.

Weber (2011) posited that a specific apprehension regarding reliability of data storage has emerged in the Arabian Gulf countries of the United Arab Emirates (UAE) and Saudi Arabia . Several countries own legislation governing data storage on computer servers beyond national borders or jurisdiction. For example, the US Patriot Act (an Act of Congress that was signed into law by President George W. Bush on October 26, 2001) forces companies in the USA to deliver data to the government without carefully inspected warrant procedure (Carlin \& Curran, 2013), and many international firms are consequently worried about keeping critical data on USA-based cloud computer servers.

Procedures were taken lately in India, UAE, and Saudi Arabia to block the RIM (Research In Motion limited) blackberry device or to trace Blackberry servers so national governments can observe messages. This was mainly due to Blackberry's advanced method of encryption which permits for protected communication of information unreachable to security forces. Educational institutions in the Middle East could face issues in utilising cloud services because of government security concerns (Weber, 2011).

Reliability. Reliability will remain a pronounced trepidation for Middle Eastern students and school systems that apply a cloud computing. Extensive service providers in the USA and Europe could possibly be reluctant to dedicate sufficient resources as technical support to the minor markets within the Middle East. Present Internet infrastructure in the Arabian Gulf and Egypt is exceptionally volatile, as an excessive amount of international traffic in the area is supported by a limited amount of undersea cables.

(Weber, 2011).

In 2008, the South-East Asia-Middle East-West Europe 4 (SEA-ME-WE 4) cable was disconnected thus instigating Internet failure in Egypt, India and the Persian Gulf. Due to a shortage of local data centres in the developing countries, 'providers such as Amazon, Google, IBM, Microsoft, and Sun Microsystems have started to launch more data centres to host cloud computing applications in several places globally to deliver redundancy and warrant reliability in the event of site outages (Al-Zoube, Abou El-Seoud, \& Wyne, 2010; Weber, 2011). 


\section{Conclusion}

In this paper, the benefits of cloud computing in higher education was highlighted. Cloud computing in developing countries was discussed particularly cloud computing status in Saudi Arabia. Characteristics of academic institutions, benefits of cloud computing for education and the adoption barriers in developing countries were explored. The study has been useful in offering important insights for academic institutions on the key incentive and barriers to cloud computing adoption in the context of developing countries and Arabic countries in particular.

\section{References}

Al Alhareth, Y., McBride, N., Prior, M., Leigh, M., \& Flick, C. (2013). Saudi Women and E-learning. The Future of Education.

Alamri, B. H., \& Qureshi, M. R. J. (2015). Usability of Cloud Computing to Improve Higher Education. IJ Information Technology and Computer Science, 9, 59-65. https://doi.org/10.5815/ijitcs.2015.09.09

Aldraehim, M. S., Edwards, S. L., Watson, J. A., \& Chan, T. (2012). Cultural impact on e-service use in Saudi Arabia: The role of nepotism. International Journal for Infonomics (IJI), 5(3/4), 655-662.

Alghamdi, I. A., Goodwin, R., \& Rampersad, G. (2011). E-government readiness assessment for government organizations in developing countries. Computer and Information Science, 4(3), 3. https://doi.org/10.5539/cis.v4n3p3

Alghamdi, I. A., Goodwin, R., \& Rampersad, G. (2011, November). A suggested e-Government Framework for assessing organizational E-readiness in developing countries. In International Conference on Informatics Engineering and Information Science (pp. 479-498). Springer Berlin Heidelberg. https://doi.org/10.1007/978-3-642-25453-6_41

Alghamdi, I. A., Goodwin, R., \& Rampersad, G. (2013). Evaluation of organizational e-government readiness in the public sector. International Journal of E-Services and Mobile Applications (IJESMA), 5(2), 1-21. https://doi.org/10.4018/jesma.2013040101

Alghamdi, I. A., Goodwin, R., \& Rampersad, G. (2016). Ready, Set, Govern: Readiness of Saudi Arabian Organizations for E-Government. International Journal of Electronic Government Research (IJEGR), 12(1), 69-98. https://doi.org/10.4018/IJEGR.2016010104

Alhammadi, A., Stanier, C., \& Eardley, A. (2015). The Determinants of Cloud Computing Adoption in Saudi Arabia. Computer Science \& Information Technology, 55. https://doi.org/10.5121/csit.2015.51406

Aljenaa, E., Al-Anzi, F., \& Alshayeji, M. (2011). Towards an efficient e-learning system based on cloud computing. Paper presented at the Proceedings of the Second Kuwait Conference on e-Services and e-Systems. https://doi.org/10.1145/2107556.2107569 10.1145/2107556.2107569

Alsanea, M. (2015). Factors Affecting the Adoption of Cloud Computing in Saudi Arabia's Government Sector (Doctoral dissertation, University of London).

Alshuwaier, F., Alshwaier, A., \& Areshey, A. (2012). Applications of cloud computing in education. 2012 8th International Conference on Computing and Networking Technology (INC, ICCNT and ICMIC), Gueongju, 2012, 26-33.

Alshwaier, A., Youssef, A., \& Emam, A. (2012). A new trend for E-learning in KSA using educational clouds. Advanced Computing, 3(1), 81. DOI: 10.5121/acij.2012.3107

Al-Somali, S., \& Baghabra, H. (2016). Investigating the Determinants of IT Professionals' Intention to Use Cloud-Based Applications and Solutions: An Extension of the Technology Acceptance. International Journal of Cloud Applications and Computing (IJCAC), 6(3), 45-62. https://doi.org/10.4018/IJCAC.2016070104

Alzahrani, M. E., \& Goodwin, R. D. (2012). Towards a UTAUT-based model for the study of E-Government citizen acceptance in Saudi Arabia. In Proceedings of World Academy of Science, Engineering and Technology (No. 64). World Academy of Science, Engineering and Technology. Retrieved from http://scholar.waset.org/1999.10/8905

Al-Zoube, M., Abou El-Seoud, S., \& Wyne, M. F. (2010). Cloud computing based e-learning system. International Journal of Distance Education Technologies (IJDET), 8(2), 58-71. https://doi.org/10.4018/jdet.2010040105 
Armbrust, M., Fox, A., Griffith, R., Joseph, A. D., Katz, R., Konwinski, A., . . Stoica, I. (2010). A view of cloud computing. Communications of the ACM, 53(4), 50-58. https://doi.org/10.1145/1721654.1721672

Buller, A. (2016). Saudi Arabia could warm to cloud computing, so long as regulation and connectivity keep pace. Retrieved from http://www.computerweekly.com/

Carlin, S., \& Curran, K. (2013). Pervasive and Ubiquitous Technology Innovations for Ambient Intelligence Environments. Information Science Reference, United States of America. https://doi.org/10.4018/978-1-4666-2041-4,

Chanchary, F. H., \& Islam, S. (2011). E-government based on cloud computing with rational inference agent. Paper presented at the 8th International Conference on High-capacity Optical Networks and Emerging Technologies. https://doi.org/10.1109/HONET.2011.6149830

Chow, R., Golle, P., Jakobsson, M., Shi, E., Staddon, J., Masuoka, R., \& Molina, J. (2009). Controlling data in the cloud: outsourcing computation without outsourcing control. In the Proceedings of the 2009 ACM workshop on Cloud computing security. 85-90. https://doi.org/10.1145/1655008.1655020

Communications and Information Technology Commission (CITC). (2016). Saudi Arabia's telecom regulator proposes regulating cloud computing. Retrieved from http://www.citc.gov.sa/en/mediacenter/pressreleases/Pages/20160724001.aspx.

Creeger, M. (2009). Cloud Computing: An Overview. ACM Queue, 7(5), 2. DOI:10.1145/1551644.1554608

Dickinson, E. (2015). Dell to partner up with Middle East firms to build cloud services. Gulf Business. Retrieved from http://gulfbusiness.com/dell-to-partner-up-with-middle-east-firms-to-build-cloud-services/

El-Sofany, H. F., Al-Otaibi, K. F., \& Alsanea, M. S. (2012). Data Exchange Model of Patient Records inKingdom of Saudi Arabia Using Cloud Computing. International Journal of Innovation, Management and Technology, 3(5), 580. https://doi.org/10.7763/IJIMT.2012.V3.301

Greengard, S. (2010). Cloud computing and developing nations. Communications of the ACM, 53(5), 18-20. http://doi.acm.org/10.1145/1735223.1735232

International Data Corporation (IDC). (2014). Saudi Arabia Cloud, Hosted, Managed, and Outsourced Services Market 2012 Analysis and 2013-2017 Forecast. PR Newswire(Jun 30, 2014).

International Trade Administration (ITA). (2016). 2016 Top markets report: Cloud computing. US Department of Commerce, International Trade Administration, Industry \& Analysis (I\&A).

Jelonek, D., \& Wysłocka, E. (2014). Barriers to the development of cloud computing adoption and usage in SMEs in Poland. Advances in Information Science and Applications, (1), 128-133.

Kaufman, L. M. (2009). Data security in the world of cloud computing. Security \& Privacy, IEEE, 7(4), 61-64. https://doi.org/10.1109/MSP.2009.87

Kaur, R. S., Sawtantar. (2015). Exploring the Benefits of Cloud Computing Paradigm in Education Sector. International Journal of Computer Applications, 115(7), 1-3. https://doi.org/10.5120/20160-2217

Kshetri, N. (2010). Cloud computing in developing economies. ieee Computer, 43(10), 47-55. https://doi.org/10.1109/MC.2010.212

Lakshminarayanan, R., Kumar, B., \& Raju, M. (2013). Cloud computing benefits for educational institutions. Second International Conference of the Omani Society for Educational Technology. Oman.

Laverty, A. (2011). The cloud and Africa-Indicators for growth of cloud computing. The African File on WordPress.com.

Retrieved

from http://theafricanfile.com/ict/the-cloud-and-africa-indicators-for-growth-of-cloud-computing/.

Linthicum, D. S. (2009). Cloud computing and SOA convergence in your enterprise: A step-by-step guide. Pearson Education, Boston, USA.

Mell, P., \& Grance, T. (2011). The NIST definition of cloud computing, 15. Gaithersburg: National Institute of Standards and Technology. https://doi.org/10.6028/NIST.SP.800-145

Mezghani, K., \& Ayadi, F. (2016). Factors Explaining IS Managers Attitudes toward Cloud Computing Adoption. International Journal of Technology and Human Interaction (IJTHI), 12(1), 1-20. https://doi.org/10.4018/IJTHI.2016010101

Ograph, B., \& Morgens, R. (2008). Cloud computing. Communications of the ACM, 51(7). 
https://doi.org/10.1145/1364782.1364786

Pardeshi, V. H. (2014). Cloud computing for higher education institutes: architecture, strategy and recommendations for effective adaptation. Procedia Economics and Finance, 11, 589-599. https://doi.org/10.1016/S2212-5671(14)00224-X

Rena, R. (2010). Emerging trends of higher education in developing countries. Analele Stiintifice ale Universitatii" Alexandru Ioan Cuza" din Iasi-Stiinte Economice, 2010, 301-316.

Susanto, T. D., \& Goodwin, R. (2010). Factors influencing citizen adoption of SMS-based eGovernment services. Electronic Journal of E-Government, 8(1), 55-71.

Tashkandi, A., \& Al-Jabri, I. (2015). Cloud computing adoption by higher education institutions in Saudi Arabia: Analysis based on TOE. Paper presented at the 2015 International Conference on Cloud Computing (ICCC). https://doi.org/10.1109/CLOUDCOMP.2015.7149634

Task Force on Higher Education and Society. (2000). Higher education in developing countries: Peril and promise. Washington DC: World Bank. Retrieved from http://documents.worldbank.org/curated/en/345111467989458740/Higher-education-in-developing-countries-peri l-and-promise

TOP500. (2016). Retrieved November 2016, from https://www.top500.org/lists/2016/11/

Troshani, I., Rampersad, G., \& Wickramasinghe, N. (2011). On Cloud Nine? An Integrative Risk Management Framework for Cloud. In 24th Bled Conference (pp. 15-26).

Troshani, I., Rampersad, G., \& Wickramasinghe, N. (2013). Managing SaaS risk in higher education organisations: A case study. International Journal of E-Business Research (IJEBR), 9(2), 8-23. https://doi.org/10.4018/jebr.2013040102

Truong, H.-L., Pham, T.-V., Thoai, N., \& Dustdar, S. (2012). Cloud computing for education and research in developing countries. In Cloud computing for education and research, 78-94. https://doi.org/10.4018/978-1-4666-0957-0.ch005

Weaver, D. (2013). Six advantages of cloud computing in education. Retrieved from http://www. pearsonschoolsystems. com/blog.

Weber, A. S. (2011). Cloud computing in education in the Middle East and North Africa (MENA) region: Can barriers be overcome? eLearning and Software for Education(eLSE) Journal, 2011, (1).

Yamin, M., \& Al Makrami, A. A. (2015). Cloud Computing in SMEs: Case of Saudi Arabia. Our Major Indexing at International Level, 4852, 853.

Yesser. (2016). Government Cloud Computing. Retrieved from http://www.yesser.gov.sa/en/BuildingBlocks/Pages/GCloud_Computing.aspx

Zeineldin, Y. (2014). Gulf cloud computing market poised to grow sevenfold. Gulf News.

Zhang, Q., Cheng, L., \& Boutaba, R. (2010). Cloud computing: state-of-the-art and research challenges. Journal of Internet Services and Applications, 1(1), 7-18. https://doi.org/10.1007/s13174-010-0007-6

\section{Copyrights}

Copyright for this article is retained by the author(s), with first publication rights granted to the journal.

This is an open-access article distributed under the terms and conditions of the Creative Commons Attribution license (http://creativecommons.org/licenses/by/4.0/). 